\title{
Size Effect Study of Sawdust Ash-Concrete under Compressive Load
}

\author{
Comingstarful Marthong \\ Lecturer, Civil Engineering Department, Shillong Polytechnic, Shillong, Meghalaya, India
}

\begin{abstract}
This study investigated the size effect phenomenon for plain-concrete and concrete inclusion with $10 \%$ sawdust ash (SDA) as partial replacement of cement. A geometrically similar plain-concrete and sawdust ash-concrete cylinder of different sizes were cast. Compressive strength was evaluated at the age of 28 and 90 days. Bažant size effect law was used to investigate the possible existence of size effect. Results from the test showed the existence of size effect in both plain-concrete and sawdust ash-concrete and followed closely the size effect law proposed by Bažant. The size effect was observed to be more for sawdust ash-concrete as compare to concrete with pure cement. Further, the size effect of sawdust ash-concrete is more pronounce at the age of 28 days as compared to 90 days strength.
\end{abstract}

Keywords: Sawdust ash, Concrete, Strength, Size effect, Bažant.

\section{INTRODUCTION}

The principle of solid mechanics supports that material properties like tensile or compressive strengths are not scale dependent. Such properties measured by testing standard laboratory samples of the material are usually assumed applicable in all the engineering practices. Available theories of material behavior that predict size effects are receiving increasing attention in the technical literature nowadays. It has been demonstrated that the size of the specimen plays an important role. Concrete is a heterogeneous material, which is generally full of micro cracks. Upon loading, these micro cracks propagate and the accumulation of such micro cracks leads to a major crack and finally ends in failure. It is well established that the mathematical modeling of such behavior should be based on the principles of fracture mechanics. Material models based on fracture mechanics can predict a size effect, if geometrically similar specimens of different sizes are considered. In brief, the "size effect" can be stated that the nominal stress $\left(\sigma_{N}\right)$ at failure decreases as the characteristic dimension $(D)$ of the structure is increased. Many researchers tried to correlate the result of $\sigma_{N}$ found by testing specimens with the size effect law proposed by Bažant [1].

Pozzolanic definition by ASTM C-618 [2] is a siliceous or siliceous and aluminous material which, in itself, possesses little or no cementitious value but which will, in finely divided form in the presence of moisture, react chemically with calcium hydroxide at ordinary temperature to form compounds possessing cementitious properties.

Many researches are being done on the possible use of locally available materials to partially replace cement in concrete as cement is widely noted to be most expensive constituents of concrete. Experimental investigation to evaluate the possibility of using Sawdust Ash (SDA) as a construction material has been reported by various researchers $[3,4,5]$. Experiments of various forms of sawdust ash-concrete specimens have been carried out without varying the specimen size. Therefore, the available results cannot be used directly for prototype implementation in actual field because of differs in the size of specimen. The optimum percentage of SDA added in concrete depends on the sources of sawdust. However, researchers reported an optimum amount varies from $5-10 \%$ for which SDA concrete has lesser effect on the strength at the later age. Therefore, in the present study $10 \%$ replacement by SDA on cement was considered.

\section{SIZE EFFECT LAW}

The size effect implies the dependence of strength of structure on its size. The size dependency of concrete structures may be described by the size effect law proposed by Bažant [1] covering various practical cases. The mathematical expression of this law is given as

$$
\sigma_{N_{U}}=\frac{B f_{t}^{\prime}}{\sqrt{1+\frac{D}{D_{0}}}}
$$

where, $f_{t}^{\prime}$ is the tensile strength of concrete, $B$ and $D_{0}$ are two empirical constants depending on the shape of structures and obtained by linear regression analysis of the test results. $D / D_{0}$ is the relative structural size ratio. The strength is usually defined as nominal stress at peak load. There are various possible correlations of the size 
effect, but bi-logarithmic representation is the most accepted one. In bi-logarithmic plot, log $\sigma_{N_{U}}$ is plotted against $\log D$. Fig. 1 show a typical plot where strength theory based on yield or strength criteria predicts no size effect, represented by horizontal line. The size effect is stronger with the response lying closer to the linear elastic fracture mechanics (LEFM) and asymptote i.e. with a slope of $-1 / 2$.

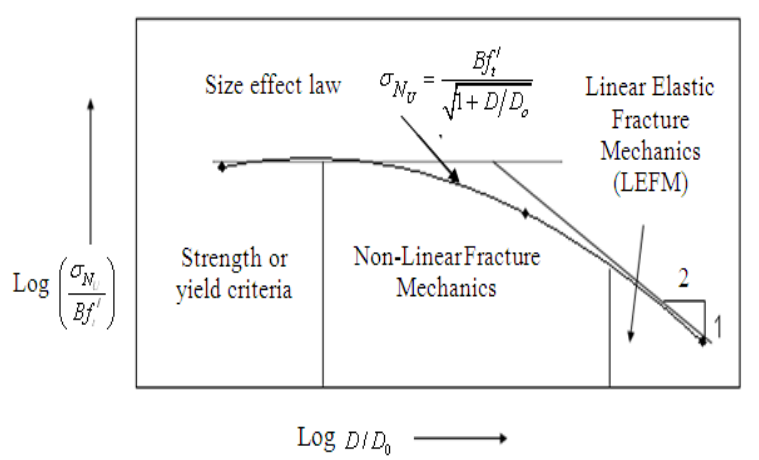

Fig. 1 Plot of size effect law [Bažant, 1984]

\section{REVIEW ON SIZE EFFECT OF CONCRETE STRUCTURAL ELEMENT}

The experimental research on size effect of concrete structural elements may be traced long back in 1925 [6]. Sener et al. [7] tested two groups of RC beams with various sizes. The results revealed the existence of a significant size effect, which was approximately described by the size effect law proposed by Bažant. Krauthammer et al. [8] investigated numerically and experimentally the size effect phenomenon of high strength concrete (HSC) for a cylindrical specimens that subject to axial load impact. Results from their tests and simulations showed the existence of a size effect in NSC cylinders under impact loading. Sener et al. [9] tested a large number of geometrically similar columns with three different slenderness ratios. The size effects become stronger as the slenderness ratio increases. Elfahal et al. [10] investigated numerically and experimentally the size effect phenomenon of normal strength concrete (NSC) for a cylindrical specimens that subject to axial load impact. Results from their tests and simulations showed the existence of a size effect in NSC cylinders under impact loading. Bindiganavile and Banthia [11] studied size effect of plain concrete beam under impact loading. The result of the impact test fitted to Bažant's size effect law. Koc and Sener [12] tested geometrically similar columns of different sizes with different types of notches for both normal and high strength concrete to study the size effect. Axial loads were applied to the specimens till failure. The bi-logarithmic plots in all the cases followed Bažant's size effect law. Choudhury [13] tested beam-column joints with nine controls and nine retrofitted of three different sizes for size effect study. The bi-logarithmic plots in both cases follow closely the size effect law. Marthong [14] tested beam-column connections specimens with eighteen controls and rehabilitated specimens of three sizes under two different cyclic loading frequencies for size effect study. The bi-logarithmic plots in both cases follow closely the size effect law. Marthong [15] tested twenty four geometrical similar fly ash concrete cylinders with four different sizes. The bi-logarithmic plots shows the effect in size is more pronounce at the early age of concrete strength.

Literature survey shows researchers correlated the existence of size effect with the size effect law proposed by Bazant [1]. Size effect study has been carried out on various concrete structural elements including plain, high strength and even for fly ash concrete. The review of literature however, could not find any size effect study related to SDA concrete. Thus, it was felt necessary to explore the possibility of existence of size effect when OPC was partially replaced by SDA.

\section{EXPERIMENTAL PROGRAM}

Experimental investigations are carried out on concrete cylinders. Four different sizes as shown in Fig. 2 were considered. Aggregate was scale down appropriately. The mix was designed for target cube strength of $30 \mathrm{MPa}$ at 28 days with water-cement ratio of 0.38 . OPC of 53 grades was partially replaced with $10 \%$ SDA by weight [5]. The compressive strength was examined at 28 days and long term contribution up to 90 days. Therefore, six specimens were cast per size of sample for strength test. Specimen sizes and detail proportions are shown in Table 1. Coarse aggregate from crushed basalt rock was use. River sand was used as fine aggregate. Materials used have been tested as per relevant codal provisions [16, 17]. Ordinary Portland cement (OPC) of 53 grades classified by BIS [18] was used. Sawdust collected from local saw mill was used in this study. The sawdust was openly heated to about the temperature of $600{ }^{\circ} \mathrm{C}$; the ash was then grounded after cooling and graded in accordance [19]. 


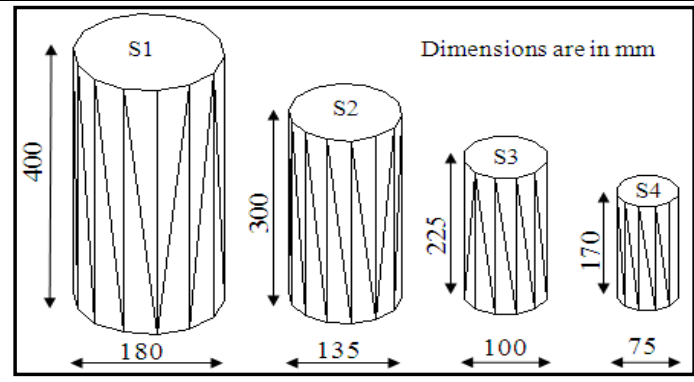

Fig. 2 Concrete specimen sizes

\section{ROLE OF SDA ON CEMENTITIOUS AND CONCRETE PROPERTIES}

The fineness of SDA is required to be equal or finer than cement for its good cementing efficiency. Fineness of OPC in this investigation is found to be $6 \%$ residue on 90 micron sieve, while that of SDA is 5\%. This show that SDA is of finer and hence can be expected to have appreciable influence on the strength development on concrete.

Normal consistency of cement with inclusion of SDA increased as compared to pure cement. Hence more water is required for wetting the particles, as the total surface area of the particle is increases.

Setting time of cement with inclusion of SDA increased as compared to pure cement paste. This behavior may be due to the low rate of hydration in the paste containing SDA.

Workability of concrete increased with the inclusion of SDA in comparison to that of concrete with pure cement. Therefore, it can be inferred that to attain the required workability, mixes containing SDA will required higher water content than the corresponding conventional mixes.

Table 2 presents the compressive strength for different combination at different ages of 28 and 90 days. It is seen that strength of concrete decreases with inclusion of SDA in all sizes. However, the gain in strength by the smaller specimens at the age of 90 days is better as compared to the larger specimen size.

Table 1 Specimen sizes and detail proportions of OPC and SDA

\begin{tabular}{|c|c|c|c|c|}
\hline Symbols & Replacement Ratio & Mark & $\begin{array}{c}\text { Sizes, mm } \\
{[\text { meight(H) x diameter(D)] }}\end{array}$ & Nos. \\
\hline SDA-0 & $100 \%$ OPC+0\% SDA & S1 & $400 \times 180$ & 6 \\
& & S2 & $300 \times 135$ & 6 \\
& & S3 & $225 \times 100$ & 6 \\
& & S4 & $170 \times 75$ & 6 \\
\hline SDA-20 & $90 \%$ OPC+10\% SDA & S1 & $400 \times 180$ & 6 \\
& & S2 & $300 \times 135$ & 6 \\
& & S3 & $225 \times 100$ & 6 \\
& & S4 & $170 \times 75$ & 6 \\
\hline
\end{tabular}

Table 2 Compressive strength

\begin{tabular}{|c|c|c|c|c|}
\hline & \multicolumn{2}{|c|}{28 Days Compressive strength } & \multicolumn{2}{c|}{$\begin{array}{c}\text { 90 Days Compressive strength } \\
\left(\mathbf{N} / \mathbf{m m}^{2}\right)\end{array}$} \\
\hline Mark & SDA-0\% & SDA-10\% & SDA-0\% & SDA-10\% \\
\hline S1 & 32.56 & 24.38 & 36.23 & 28.56 \\
\hline S2 & 22.39 & 17.98 & 25.78 & 20.45 \\
\hline S3 & 15.12 & 13.32 & 18.55 & 14.81 \\
\hline S4 & 10.78 & 9.20 & 14.44 & 12.12 \\
\hline
\end{tabular}

\section{Analysis of Results For Exploring The Presence of Size Effect}

The strength is usually defined as nominal stress at peak load. Stress $\left(\sigma_{N_{U}}\right)$ in all specimens were calculated and bi-logarithmic plots were drawn. Other parameter was also considered and the possible existence of size effects was investigated.

\subsection{Bi-logarithmic plot}

Using stress $\left(\sigma_{N_{U}}\right)$ and characteristic dimension $(D)$, bi-logarithmic plots were drawn. The size effect law as proposed by Bažant [1] given in Eqn. 1 was used for the statistical regression of the data. $B$ and $D_{0}$ are the two unknown constants which can be determined by statistical regression analysis. The value of tensile 

strength of concrete $\left(f_{t}^{\prime}\right)$ was calculated as $2.504 \mathrm{~N} / \mathrm{mm}^{2}$ [20]. To facilitate the evaluation of the constants in the size effect law, Eqn. 1 can be rearranged as follows:

$$
\left(\frac{f_{t}^{\prime}}{\sigma_{N_{U}}}\right)^{2}=\frac{1}{D_{0} B^{2}} \cdot D+\frac{1}{B^{2}}
$$

The above equation is of the form of $Y=A X+C$ where $Y=\left(f_{t}^{\prime} / \sigma_{N_{U}}\right)^{2}, X=D$ and the constants $C$ and $A$ are given by $C=\frac{1}{B^{2}}$ and $A=\frac{1}{D_{0} B^{2}}$, Hence value of $\mathrm{B}$ and $D_{0}$ are $B=\frac{1}{\sqrt{C}}$ and $D_{0}=\frac{C}{A}$. The typical regression analysis for concrete with $0 \%$ SDA at 28 days is shown in Fig. 3 and values of $B$ and $D_{0}$ were found to be 0.87 and 57.13 respectively. Using these values, the bi-logarithmic plot were drawn with $\log \left(D / D_{0}\right)$ in the $X$ axis and $\log \left(\sigma_{N_{U}} / B f_{t}^{\prime}\right)$ in the $Y$ axis as shown in Fig. 4. Similarly, values of $B$ and $D_{0}$ for other specimens were calculated and all bi-logarithmic plot are drawn accordingly (Fig. 5 to 7). It is observed from these plots that the trend of the curve follows a horizontal line at the initial part, indicating no size effect. The curve approaches a straight line with slope of about $-1 / 2$ towards the end (LEFM zone). In the intermediate zone there is a smooth curved transitional part. Thus, it can be concluded that all plot shows presence of size effect in accordance with Bažant's size effect law. However, size effect of SDA-concrete was observed to be more prominent for the specimens tested at 28 days as compared to that of 90 days.

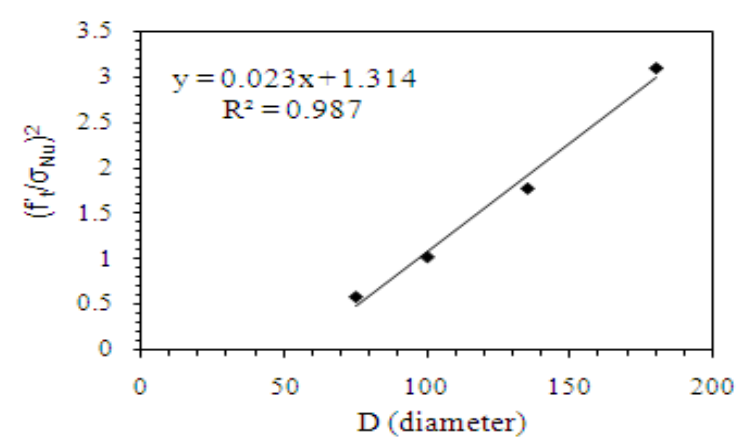

Fig. 3 Typical regression plot

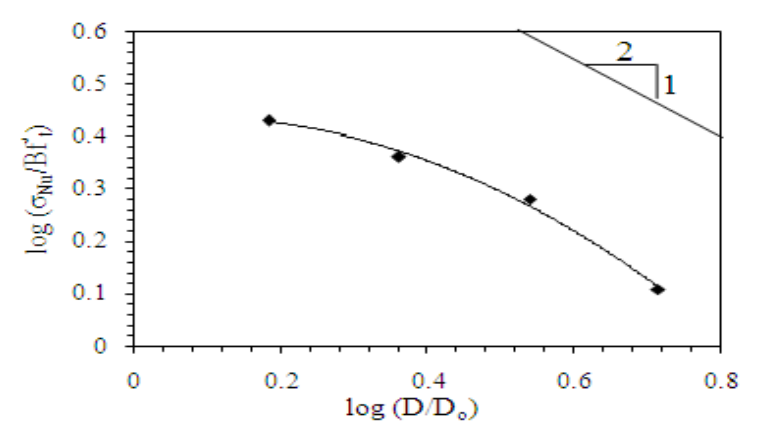

Fig. 4 Bi-logarithmic plot for 0\% SDA at 28 days

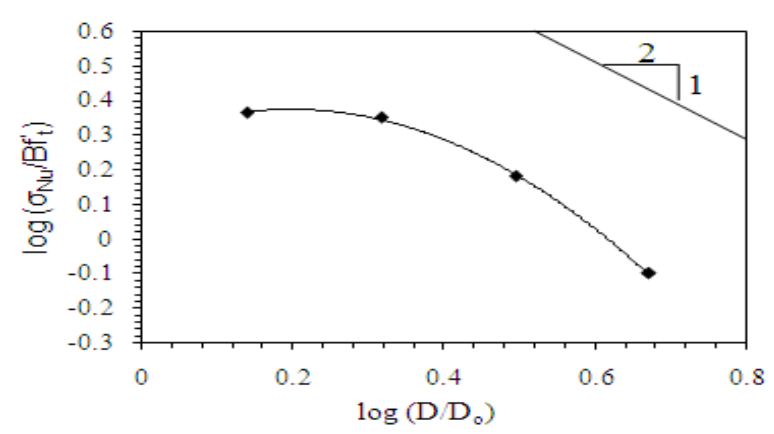

Fig. 5 Bi-logarithmic plot for $10 \%$ SDA at 28 days 


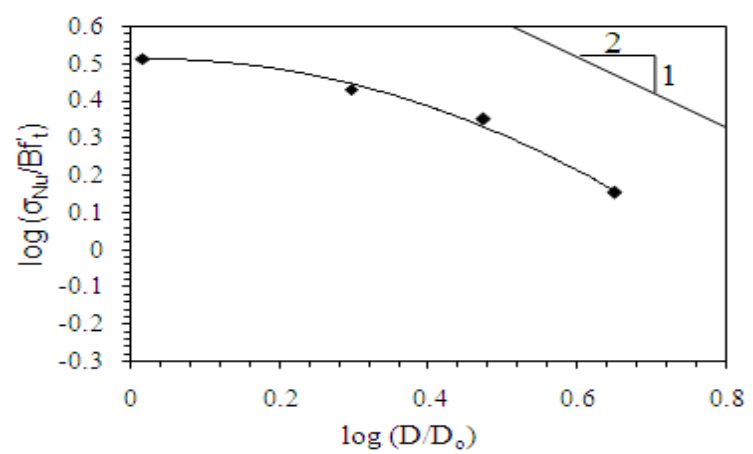

Fig. 6 Bi-logarithmic plot for 0\% SDA at 90 days

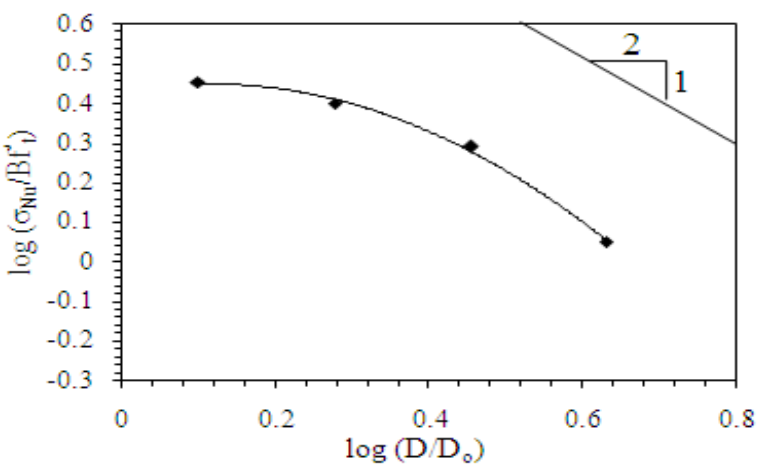

Fig. 7 Bi-logarithmic plot for $10 \%$ SDA at 90 days

\subsection{Size effect on gain in ultimate strength}

The compressive strength of all specimens at age of 28 and 90 days are shown in Table 2. The contribution to long term gain in strength at 90 days over the 28 days was calculated. It is observed that cement replacement by SDA has lesser effect on the strength at the later age. The variation of this gain is presented in Fig. 8. This clearly indicates that the gain in strength increases as the specimen size decreases supporting the size effect principle.

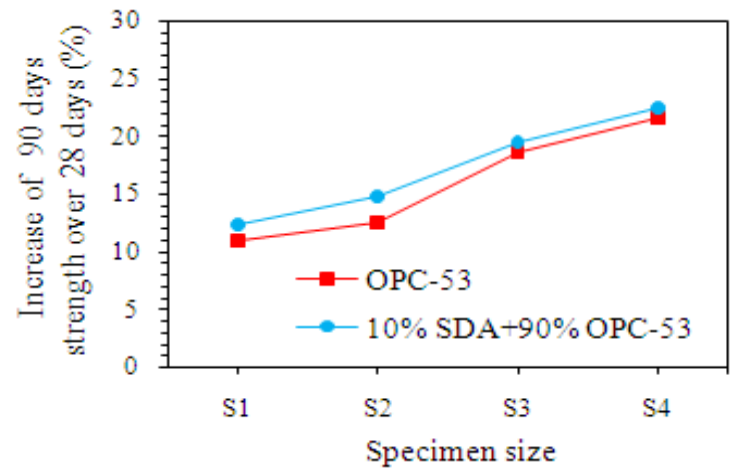

Fig. 8 Gain of strength at 90 days over 28 days

\section{Conclusions}

Analyzed results were used for drawing bi-logarithmic plot. For the purpose of statistical regression of data, the size effect law proposed by Bažant [1] was used. Different plots were drawn for concrete strength with $0 \%$ and $10 \%$ replacement by SDA. Strength test were performed at 28 and 90 days. In all cases studied, it was found that these graphs followed the well established size effect law as proposed by Bažant [1]. It was also noted that, the gain in long term strength for small specimen was the maximum and it decreased as the specimen size increased. This is an indication for existence of size effect. The size effect was observed to be more for sawdust ash-concrete as compare to concrete with pure cement. Further, the size effect of sawdust ash- concrete is more pronounce at the age of 28 days as compared to 90 days strength. 


\section{References}

[1] Bažant, Z. P. (1984). Size effect in blunt fracture: Concrete, rock, metal. Journals Engineering Mechanics, ASCE, 110(4): $518-535$.

[2] ASTM C 618 (1978). Specification for pozzolanas, Philadelphi.

[3] Sumaila, S. A., and Job, O. F. (1999). Properties of SDA-OPC concrete: A preliminary assessment. Journal of Environmental Science. Vol.3 (2), pp. 155-159.

[4] Udoeyo, F.F., and Dashibil, P.U. (2002). Sawdust Ash as Concrete Material. Journal of Materials in Civil Engineering. ASCE, Vol. 14(2): 2002, 173.

[5] Marthong, C. (2012a). Sawdust Ash (SDA) as Partial Replacement of Cement. International Journal of Engineering Research and Applications (IJERA) ISSN: 2248-9622, Vol. 2 (4), pp.1980-1985.

[6] Sabnis, G., M, and Mirza, M., S (1979). Size effects in model concrete. Journal of Structural Division, ASCE, 105(ST6), 1007-1020.

[7] Sener, S., Bažant, Z. P., and Becq-Giraudon, E. (1999). Size effect on failure of bond splices of steel bars in concrete beams. Journals of Structural Engineering, ASCE, 125(6), 653-660.

[8] Krauthammer, T., Elfahal, M. M., Ohno, T., Beppu, M., and Mindess, S. (2003). Size effect of high strength concrete cylinder subjected to axial impact. International Journals of Impact Engineering, Elsevier, 28, 1001-1016.

[9] Sener, S., Barr BIG, and Abusiaf, H. F. (2004). Size effect in axially loaded reinforced column. Journal Structural Engineering, ASCE, 130(4):662-670.

[10] Elfahal, M. M., Krauthammer, T., Ohno, T., Beppu, M., and Mindess, S. (2005). Size effect of normal strength concrete cylinder subjected to axial impact. International Journal of Impact Engineering, Elsevier, 31,461-481.

[11] Bindiganavile, V., and Banthia, N. (2006). Size effects and the dynamic response of plain concrete. Journal of Materials in Civil Engineering, ASCE, 18(4), 485-491.

[12] Koc, V., and Sener, S. (2009). Size effect in normal- and high-strength concrete with different notches under the axial load. Journal of Materials in Civil Engineering, ASCE, 21(9), 433-445.

[13] Choudhury, A. M. (2010). Study on size effect of RC beam-column connections with and without retrofitting under cyclic loading. Doctoral Thesis, Department of Civil Engineering, Indian Institute of Technology, Guwahati, India.

[14] Marthong, C. (2012b). Experimental study on rehabilitated RC beam-column connections under cyclic loading. Doctoral Thesis, Department of Civil Engineering, Indian Institute of Technology, Guwahati, India.

[15] Marthong, C. (2012c). Size Effect Study on Fly Ash Concrete. International Journal of Engineering Research and Technology, ISSN 2278 - 0181, Accepted for publication, Vol. 1 (6).

[16] IS 2386 (1963). Methods of test for aggregates for concrete - Part 1: Particle size and shape. Bureau of Indian Standard, New Delhi.

[17] IS 2386 (1963). Methods of Test for aggregates for concrete - Part 3: Specific gravity, Density, Voids, Absorption and Bulking. Bureau of Indian Standard, New Delhi.

[18] IS 12269 (1987). Specification for OPC-53 grade cement. Bureau of Indian Standard, New Delhi.

[19] British Standard Institution (1967). Methods for sampling and testing of mineral aggregate, Sands and Fillers, BS. 812.

[20] IS 456 (2000). Plain and reinforced concrete - Code of Practice. Bureau of Indian Standard, New Delhi. 